\title{
WEB CAM SENSING USING SDK TOOL
}

\author{
Monali S. Dhotarkar ${ }^{1}$, Ruchita R. Chilamwar ${ }^{2}$, Sarojinee A. Tarale ${ }^{3}$, AnsarI. Sheikh ${ }^{4}$ \\ ${ }^{1,2,3}$ Student, Computer Science and Engineering, ${ }^{4}$ Lecturer, Information Technology, SRMCEW, Maharashtra, India
}

\begin{abstract}
Microsoft Touchless SDK (Software Development) introduces a new way of interacting with the computers by means of object tracking through webcams. Unlike other traditional input devices like mouse or keyboard, the input data from Touchless SDK (markers ,position data) are usually unstable and inaccurate in nature, which limits the application of Touchless device as a replacement of the traditional input devices. In this paper, we explore a new way of utilizing the convenience of Touchless device by combining Free hand writing, drawing and touchless motion gaming. etc. without specialized device like lightpen or touchscreen, Touchless device provides pretty good performance of speed and accuracy.
\end{abstract}

Key Words: Touchless SDK(Software Development Kit), Web camera, Object Tracking.

\section{INTRODUCTION}

In today's fast developing world newer and latest technologies are replacing the old once. The latest technologies are more efficient in performing their assigned work as well as fast and more precious in their task. In the developing phase of computer, The size of computer was like a room; due to advanced study and technology existing system replaced by latest technology as a output we have small size computers. [4] Though new and latest technology is coming in the market but this upcoming technology has one drawback i.e. cost. Cost is directly proportional to product, So cost affects the product directly. So keeping in mind this drawback of current system we would like to introduce our system which is with all new, latest technology and with minimum cost [5].

Touchless started as Mike Wasserman's college project at Columbia University. Mike presented the project at the Microsoft Office Labs Productivity Science Fair, Office Labs fell in love with it, and Touchless was chosen as a Community Project.[1] Our deliverables include an extensible demo application to showcase a limited set of multi-touch capabilities, but mainly we are delivering an SDK to allow users to build their own multi-touch applications.

\section{EXISTING SYSTEM}

In today's generation we are using touchscreen technology in devices like Smartphone, tablets, etc. A touchscreen is a electronic visual display that the user can control through simple or multi touch by touching the screen with one or more fingers. Some touchscreens can also detect objects such as stylus or ordinary or specially coated gloves. The user can use the touchscreen to react to what is displayed and to control how it is displayed. But the main disadvantage of the touchscreen technology is it requires expensive hardware component i.e. Sensor and the electronic display which requires more maintenance and precaution which increases its complexity for use.

\section{OBJECTIVES}

We are going to develop a software that will take any object as a touchless pointing device and can performs functions like free hand writing, free hand drawing, image controlling i.e. zoom in, zoom out, scrolling and rotating [3]

\section{PROPOSED SYSTEM}

\subsection{FrameWork}

The framework mainly consists of three option that are Camera, Marker and Application. The camera option is use to integrate the web camera setting within the system. The Marker option enables the user to make use of functions like free hand drawing (Fig.5), zooming and it detects the color which is supported by "Artificial Intelligence" (Fig.4). In Application option user can implement the required module i.e. draw module, image module and gaming, etc [4]. The demonstration is proceeds and stops by using this option.

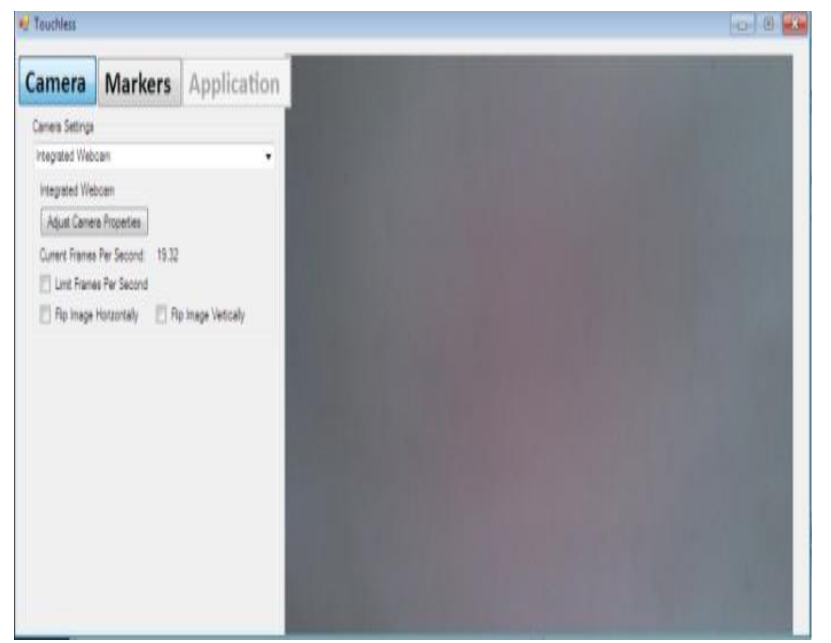

Fig-1: Framework View 


\subsection{Architecture}

The architecture of proposed system is as follows which uses the properties of all modules of a system.

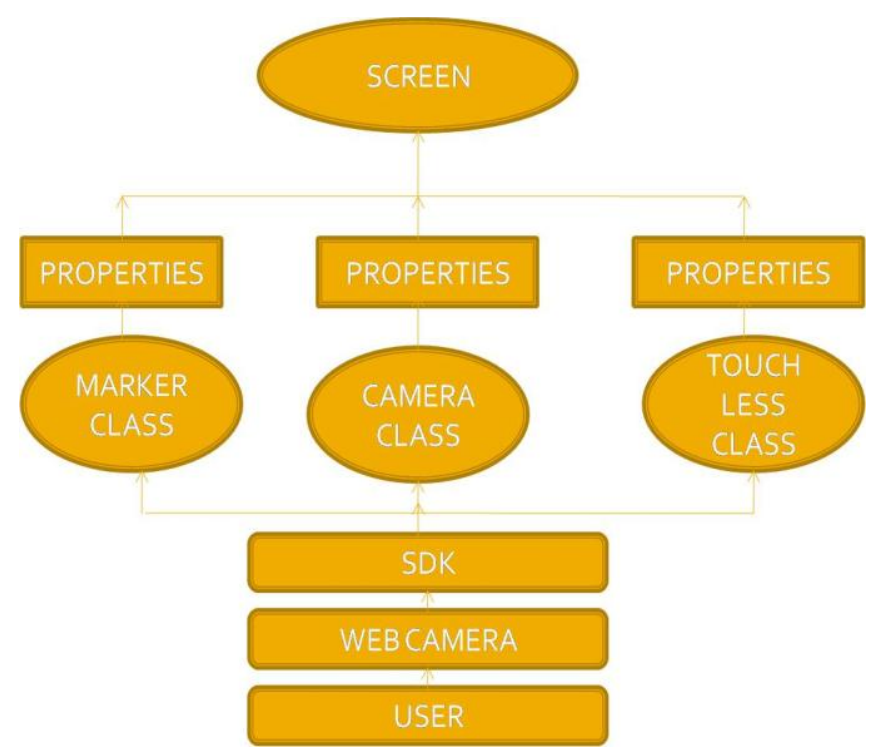

Fig-2: Architecture of proposed system.

The architecture follows the bottom-up approach of system. The user interface begins with interaction with the web camera, i.e. integrated within the system. The web camera access dynamic link library like WebCamLib property associated by SDK.[8]The SDK is aggregated with higher classes such as Marker, camera, touchless classes, which uses the properties of their own classes provided by SDK tool. This all forms the strong frame work that provide better user interface for the user [7].

\section{WORKING}

The basic working of the system is very easy to understand. The user interfaces with the web camera by taking any object like pen, stick, finger, etc; (Fig.3) which acts like marker by making use of this marker user can perform the different applications (Fig.6). Moreover, this marker can detect any color, this phenomenon defined that here Artificial Intelligence is used(Fig.4). One more feature is added that at the same time two markers can be worked efficiently i.e. dual marking. This concept of dual marking mainly use for gaming purpose. Means, two users can play game at the same time.

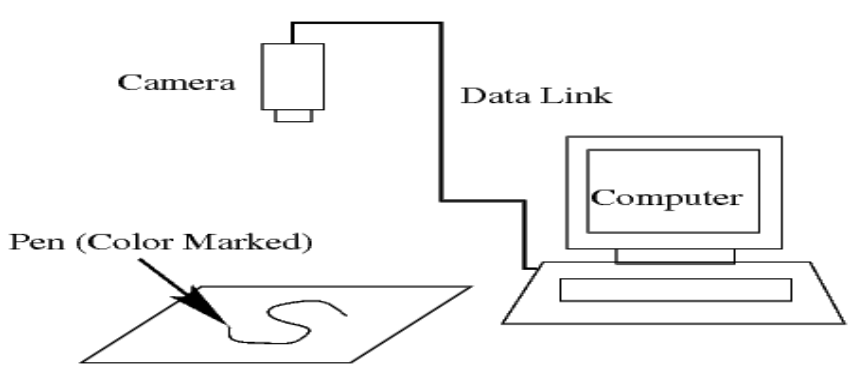

Fig-3: The Hardware Configuration

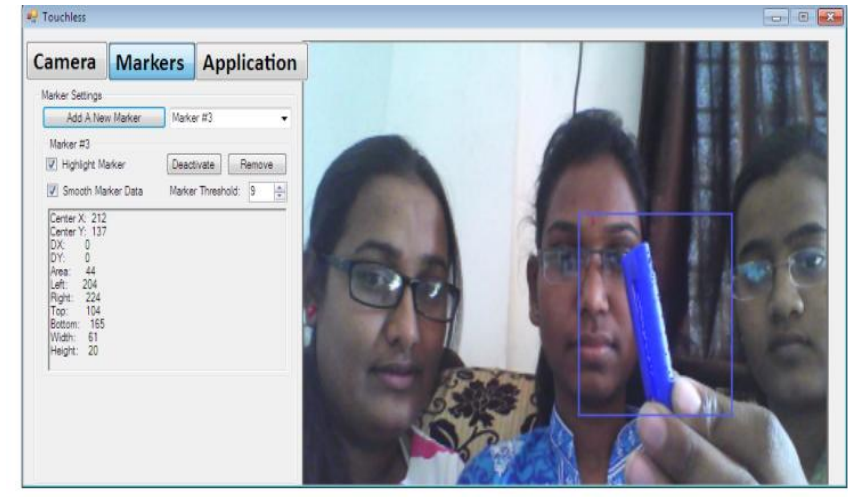

Fig-4:Color Detection

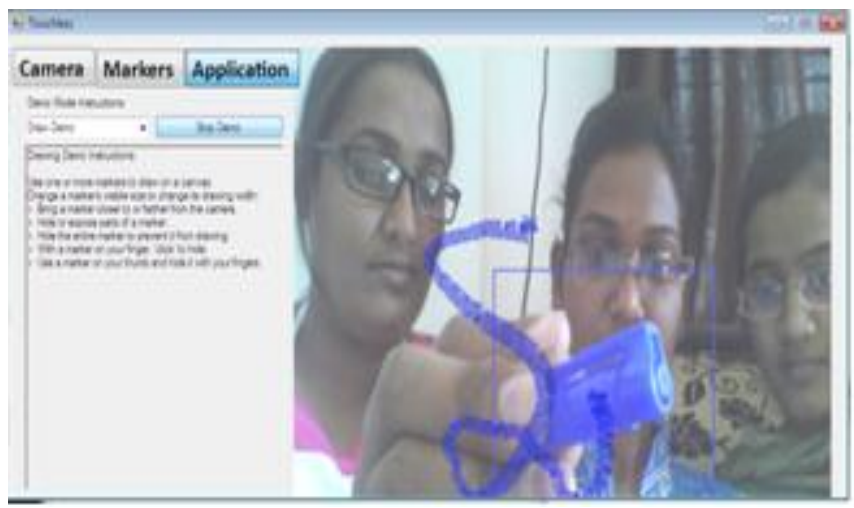

Fig-5:Free Hand Writing

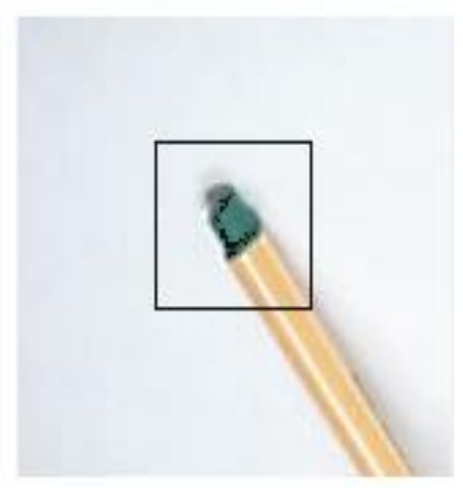

Fig-6: Object Tracking In Action

\section{BENIFITS}

The main advantage of this project is that it requires minimum software because there are no additional hardwares are use like sensors, etc to sense the object touchlessly, Moreover, any object can be use as pointing device like finger, stick, etc [5] .It can capture any color of pointing device. It supports dual marking also i.e. at a time two users can use applications like games.

\section{APPLICATION}

The touch less technology can be used in vast number of applications such as, we can perform various computer work just like we are doing with mouse and keyboard

$>$ Free hand writing 
$>$ Free hand drawing

$>$ Image controlling

$$
\begin{array}{ll}
\checkmark & \text {-zoom in } \\
\checkmark & \text {-zoom out } \\
\checkmark & \text {-scrolling of image } \\
\checkmark & \text {-rotating of image }
\end{array}
$$

Touch less game

\section{CONCLUSION}

The project title "Web cam sensing using touchless SDK" is software to experience multitouch applications. It will be cheap and latest technology which will over come out flows of current system.

\section{ACKNOWLEDGEMENT}

We would like to extend our heartfelt thanks to our guide Mr. Ansar Sheikh and acknowledge his able guidance and constant encouragement, which went a long way in ensuring our success. His vast knowledge and experience in the field of Computer was of immense help to us during the preparation of our journal paper.

\section{REFERENCES}

[1] http://www.touchuserinterface.com/2008/ 09/touchlesstouch

[2] http://technabob.com/blog/2007/03/19/the-touchlesstouchscreen-monitor/

[3] http://touchless.codeplex.comhttp://projectanalysis.wordp ress.com/ 2011/01/08/touchless-webcam-motion-sense-sdk [4] Microsoft, Internet. [Online]. Available:

http://www.officelabs.com/projects/touchless/Pages/default. aspx

[5]//www.etre.com/blog/2008/02/elliptic_labs_touchless_us er_interface

[6]www.touchuserinterface.com/2008/09/touchless-touchscreen-that-senses-your.html

[7]ProcessingGraphicsLibrarly. http://processing.org/reference/libraries.

[8] Touchless Software Development Kit. Object Tracking SDK [Online]. Available: http://touchless.codeplex.com

\section{BIOGRAPHIES}

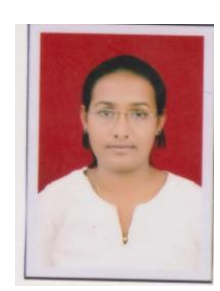

Monali Dhotarkar, is pursuing B.E Degree from SRMCEW in Computer Science and Engineering from RTMNU, Maharashtra, India.

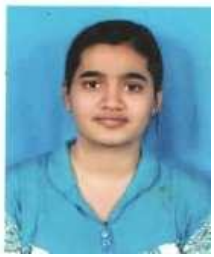

Ruchita Chilamwar, is pursuing B.E Degree from SRMCEW in Computer Science and Engineering from RTMNU, Maharashtra, India

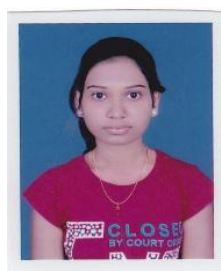

Sarojinee Tarale, is pursuing B.E Degree from SRMCEW in Computer Science and Engineering from RTMNU, Maharashtra, India

Ansar Sheikh has received the B.E. degree in Information Technology from RTMNU, Maharashtra, India pursuing M. Tech in CSE from RGPV, Bhopal, Madhya Pradesh, India. He is working in the department of IT as a lecturer in SRMCEW, Nagpur, Maharashtra, India 